\title{
Functional dyspepsia: relationship between clinical subgroups and Helicobacter pylori status in Western Turkey
}

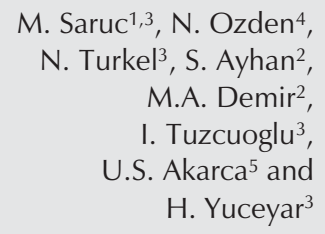

\author{
${ }^{1}$ Eppley Cancer Research Institute, and \\ ${ }^{2}$ Division of Gastroenterology and Hepatology, \\ University of Nebraska Medical Center, Omaha, NE, USA \\ Departments of ${ }^{3}$ Gastroenterology and ${ }^{4}$ Pathology, \\ Celal Bayar University, Manisa, Turkey \\ ${ }^{5}$ Department of Gastroenterology, Ege University, Izmir, Turkey
}

\section{Correspondence \\ M. Saruc \\ 6351 Sok Ege \\ Apt. 39/12 Atakent \\ Izmir \\ Turkey \\ E-mail: msaruc@hotmail.com}

This study was presented at the World Congress of Gastroenterology, Bangkok, Thailand, February 24 to March 1, 2002.

$\ldots \ldots \ldots \ldots \ldots \ldots \ldots$

Received June 14, 2002 Accepted May 13, 2003

\begin{abstract}
The etiology of functional dyspepsia is not known. The objective of the present study was to determine the characteristics of functional dyspepsia in Western Turkey. We divided 900 patients with functional dyspepsia into three subgroups according to symptoms: ulcer-like (UL), 321 (35.6\%), motility disorder-like (ML), 281 (31.2\%), and the combination (C) of these symptoms, 298 (33.1\%). All patients were submitted to endoscopic evaluation, with two biopsies taken from the cardia and corpus, and four from the antrum of the stomach. All biopsy samples were studied for Helicobacter pylori ( $\mathrm{Hp}$ ) density, chronic inflammation, activity, intestinal metaplasia, atrophy, and the presence of lymphoid aggregates by histological examination. One antral biopsy was used for the rapid urease test. Tissue cagA status was determined by PCR from an antral biopsy specimen by a random sampling method. We also determined the serum levels of tumor necrosis factor- $\alpha$ (TNF- $\alpha$ ) and gastrin by the same method. Data were analyzed statistically by the Kolmogorov-Smirnov test and by analysis of variance. $H p$ and cagA positivity was significantly higher in the UL subgroup than in the others. The patients in the ML subgroup had the lowest $H p$ and cagA positivity and $H p$ density. The ML subgroup also showed the lowest level of $H p$-induced inflammation among all subgroups. The serum levels of TNF- $\alpha$ and gastrin did not reveal any difference between groups. Our findings show a poor association of $H p$ with the ML subgroup of functional dyspepsia, but a stronger association with the UL and C subgroups.
\end{abstract}

\section{Introduction}

According to Rome I criteria (1), dyspepsia is chronic and recurrent pain or discomfort centered in the epigastrium. The most
Key words - Functional dyspepsia

- Subgroups

- Helicobacter pylori

- Symptoms

................... 
after appropriate investigations $(1,2)$.

The annual prevalence of dyspepsia in western countries is approximately $25 \%$ (3). Less than half of dyspepsia sufferers in Europe and the United States seek medical help for their complaint (4). Dyspepsia is one of the most common causes of morbidity and economic loss (5). Patients with dyspepsia also have deterioration in the quality of their life (4). Relief of symptoms and restoration of a normal quality of life by cure of the underlying cause of symptoms must also be the aim of the management of dyspepsia.

Guidelines for the management of dyspepsia have been proposed by the American Gastroenterology Association, the Digestive Health Foundation in the United States, the Maastricht Helicobacter pylori consensus meeting in Europe, the Canadian H. pylori consensus conference, two Asian-Pacific consensus meetings, and the British Society of Gastroenterology (3,4,6-9). The role of $H$. pylori testing and treatment in patient management is a major component of all of these guidelines, although recently published data do not support the view that treatment of $H$. pylori has a beneficial effect on symptoms and quality of life (2). However, some studies have revealed the beneficial effect of treatment for $H$. pylori eradication in some dyspepsia subgroups (10).

Thus, it is reasonable to assume that there must be some subgroups of dyspepsia patients with symptoms related to $H$. pylori infection. The aim of the present study was to determine if there is any difference between the subgroups of dyspepsia according to $H$. pylori strain, infection characteristics and outcomes.

\section{Material and Methods}

\section{Subjects}

From December 1999 to November 2001, 900 patients (417 males and 483 females, mean age: $45.7 \pm 17.3$ years) with functional dyspepsia seen at the Gastroenterology Outpatient Clinic, Celal Bayar University Hospital, Manisa, Turkey, were enrolled in the study. Patients were excluded if they had received nonsteroidal anti-inflammatory drugs, bismuth compounds, proton pump inhibitors, oral anticoagulants, or antibiotics known to be active against $H$. pylori within the previous three months, as were those who had received recent blood transfusions, had undergone gastric surgery, or had bleeding diathesis. Patients with a gastric or duodenal ulcer, a gastric outlet obstruction, and reflux disease were also excluded.

\section{Study design}

The symptoms of the patients were recorded according to the Glasgow dyspepsia severity scale. The patients were divided into three subgroups according to their dominant dyspepsia symptom: ulcer-like dyspepsia (UL), motility disorder-like dyspepsia (ML), and the combination (C) of these symptoms $(2,10)$. Subjects underwent an upper gastrointestinal endoscopy and biopsy specimens were taken from the gastric antrum, body, and fundus.

\section{Endoscopy}

Endoscopy was performed under sedation with 0 to $5 \mathrm{mg}$ of intravenous midazolam. A GIF1T-30 gastroscope (Olympus Optical Company Ltd., Tokyo, Japan) was used and was thoroughly cleaned and disinfected between endoscopies by internal and external brushing with a neutral detergent, washing in an endoscope washer (model EW-20, Olympus), and a further 7-min wash with neutral detergent, followed by 4-min disinfection with $2.2 \%$ glutaraldehyde.

To determine the status of $H$. pylori infection, biopsy specimens were taken from the antrum (within $2 \mathrm{~cm}$ of the pylorus, two for histology and one for the rapid urease test), corpus (half-way along the greater cur- 
vature, two for histology), and fundus (high in the fundal vault, two for histology). We also took an additional biopsy from the esophagus in all subgroups to determine the presence of normal esophageal mucosa. An antral specimen was immediately placed in a tube for the rapid urease test.

\section{Histology}

Biopsy specimens were placed in Hollande solution for histologic examination and sent to the pathology laboratory. Tissues were fixed with Hollande solution and routinely processed, embedded in paraffin and cut into 5$\mu \mathrm{m}$ sections. All sections were stained with hematoxylin-eosin plus toluidine blue in order to better reveal the bacteria. Slides were examined independently by two pathologists according to the Sydney system (11). Staging for H. pylori density, activity, chronic inflammation, and intestinal metaplasia was graded as absent, mild, moderate, and significant.

\section{Tissue cagA assay}

Tissue cagA status was determined by PCR in an antral biopsy specimen by a random sampling method as previously described (12). Furthermore, the primers 5'AATACACCAACGCCTCCAAG-3' and 5'TTGTTGCCGCCTTTGCTCTC-3' were used to amplify the cagA gene (13). PCR was performed using a DNA engine (Wizard genomic DNA purification system; Promega, Madison, WI, USA) for 35 cycles, $1 \mathrm{~min}$ at $94^{\circ} \mathrm{C}, 1 \mathrm{~min}$ at $50^{\circ} \mathrm{C}$, and $1 \mathrm{~min}$ at $72^{\circ} \mathrm{C}$. The final cycle included a $10-\mathrm{min}$ extension step at $72^{\circ} \mathrm{C}$ to ensure a full extension of the PCR product.

\section{Tumor necrosis factor- $\alpha$ and gastrin assays}

We also determined the serum levels of tumor necrosis factor- $\alpha$ (TNF- $\alpha$ ) and gastrin in $10 \%$ of the patients selected at random from all subgroups. Fasting plasma speci- mens were frozen at $-40^{\circ} \mathrm{C}$. After an average period of one month, these specimens were thawed for TNF- $\alpha$ and gastrin measurements. Serum gastrin levels were measured by radioimmunoassay (double antibody gastrin, Cat. No. KGAD1, Diagnostic Products Corporation, Los Angeles, CA, USA). TNF- $\alpha$ levels were determined by ELISA using the Amicyte kit (Warminster, PA, USA). The intra- and interassay coefficients of variation were less than 8 and $9 \%$, respectively. All measurements were performed within a single assay.

\section{Statistical analysis}

H. pylori density, cagA status, H. pylori activity, chronic inflammation, the presence of atrophy, intestinal metaplasia, the presence of lymphoid aggregates, dyspepsia score, and serum TNF- $\alpha$ and gastrin levels were all evaluated and compared between subgroups of dyspepsia.

The Kolmogorov-Smirnov test and analysis of variance were used in addition to the Mann-Whitney U-test and chi-square test for statistical analysis, with the level of significance set at $\mathrm{P}<0.05$.

The study was approved by the Hospital Ethics Committee and all patients gave written informed consent. The study was conducted in accordance with the guidelines of the declaration of Helsinki (1975).

\section{Results}

The 900 patients were divided into subgroups according to their symptoms as follows: ulcer-like (UL), 321 (35.6\%), motility disorder-like (ML), 281 (31.2\%), and the combination (C) of these symptoms, 298 (33.1\%). H. pylori infection was more frequent in the UL subgroup (79.1\%) than in the ML (53\%) subgroup ( $\mathrm{P}=0.01)$, but there was no difference when compared with the C subgroup (66.7\%) $(\mathrm{P}=0.08)$ (Table 1). cagA positivity in the UL subgroup (78.1\%) was also significantly higher than in the ML 
subgroup $(\mathrm{P}<0.001)$, but did not differ from that observed in the $\mathrm{C}$ subgroup $(\mathrm{P}>0.05)$. Also, H. pylori-associated histological changes were more common in the UL subgroup than in the other subgroups. The patients in the ML subgroup had the lowest $H$. pylori infection rate, cagA positivity and $H$. pylori density $(\mathrm{P}=0.02)$.

H. pylori density and activity were higher in the UL subgroup than in the ML subgroup $(\mathrm{P}<0.05)$. Chronic inflammation, the presence of atrophy, and intestinal metaplasia were more severe in the UL and $C$ subgroups than in the ML subgroup $(\mathrm{P}<0.05)$. Also, the UL and $\mathrm{C}$ subgroups more frequently had lymphoid aggregates than the ML subgroup $(\mathrm{P}<0.05)$. The ML subgroup showed the lowest level of $H$. pylori-induced inflammation among all subgroups $(\mathrm{P}=0.02)$ (Table 1). Serum TNF- $\alpha$ levels were found to be elevated in the UL and $\mathrm{C}$ subgroups compared with the ML subgroup ( $\mathrm{P}<0.01)$. However, serum gastrin levels did not differ between subgroups $(\mathrm{P}>0.05)$.

\section{Discussion}

The association of functional dyspepsia

\begin{tabular}{|c|c|c|c|}
\hline & UL & $\mathrm{ML}$ & C \\
\hline$N(\%)$ & $321(35.6 \%)$ & $281(31.2 \%)$ & $298(33.1 \%)$ \\
\hline H. pylori positivity & 254 (79.1\%) & $149(53.0 \%)$ & $199(66.7 \%)$ \\
\hline Tissue cagA positivity (PCR) & $25 / 32(78.1 \%)$ & $12 / 28(42.8 \%)$ & $17 / 30(60 \%)$ \\
\hline H. pylori density & $1.9 \pm 1.0$ & $1.2 \pm 0.6$ & $1.6 \pm 0.8$ \\
\hline H. pylori activity & $1.4 \pm 0.8$ & $0.7 \pm 0.3$ & $1.0 \pm 0.8$ \\
\hline Chronic inflammation & $1.8 \pm 0.7$ & $1.5 \pm 0.3$ & $1.7 \pm 1.0$ \\
\hline Presence of atrophy & $25(7.7 \%)$ & $16(5.6 \%)$ & $21(7.0 \%)$ \\
\hline Intestinal metaplasia & $0.8 \pm 0.4$ & $0.2 \pm 0.4$ & $0.54 \pm 0.3$ \\
\hline Lymphoid aggregate & $148(46.1 \%)$ & $74(26.3 \%)$ & $168(56.3 \%)$ \\
\hline TNF- $\alpha$ (pg/ml) & $11.9 \pm 7.9$ & $5.6 \pm 2.9$ & $10.3 \pm 6.3$ \\
\hline Gastrin (pg/ml) & $63.2 \pm 42.0$ & $55.3 \pm 35.9$ & $66.9 \pm 59.7$ \\
\hline
\end{tabular}

Staging for $\mathrm{H}$. pylori density, activity, chronic inflammation, and intestinal metaplasia was graded as absent, mild, moderate, and significant. Data written in bold were significantly different from the others (Kolmogorov-Smirnov test and analysis of variance). UL: ulcer-like dyspepsia; ML: motility disorder-like dyspepsia; C: combination of both symptoms. with $H$. pylori infection has been questioned since $H$. pylori and its associated histological gastritis were first identified. A significant percentage of patients with dyspepsia are infected with $H$. pylori. However, the relationship between the organism and dyspeptic symptoms has not been fully elucidated (14). Unlike the well-established role of $H$. pylori in the pathogenesis of peptic ulcer disease, the relation to functional dyspepsia is controversial (15). Many studies have examined the association between $H$. pylori and functional dyspepsia, generally with conflicting results (16-20).

Attempts to identify virulent strains of $H$. pylori, which are more likely to result in clinically important outcomes, have focused on two groups of potential bacterial virulence factors, the cag pathogenicity island (for which cagA is a marker) and the vacuolating cytotoxin, VacA (12). Although the mechanism is unknown, infection with strains that possess the cag pathogenicity island are associated with greater production of interleukin 8 than infection with strains without the island (13).

In the present study, we were able to extend the observations regarding the presence of the cagA gene and clinical outcome, and histological findings, to patients with dyspepsia in the Turkish population. We may be criticized for categorizing dyspepsia as UL, ML, and $\mathrm{C}$ according to symptom clusters. However, Talley et al. (10) recently showed that subgrouping the patients with functional dyspepsia according to their most bothersome and predominant symptom was useful in predicting the response to proton pump inhibitor therapy.

In our study, the density of $H$. pylori was directly correlated with the activity of inflammation and the presence of peptic ulcer disease. Nevertheless, the dyspepsia severity score and the presence of atrophy were not correlated with any of these parameters. Our results also agree with others suggesting that cagA positivity is associated with more 
severe inflammation and more significant gastroduodenal pathologies but not with symptom severity or clinical outcome $(2,3$, $6,8)$.

Our findings show that the association of H. pylori with the ML subgroup of func- tional dyspepsia was poor, but was stronger in the UL and $\mathrm{C}$ subgroups. Our results also confirm that cagA-positive strains of $H$. $p y$ lori cause greater histological changes which can be predicted by determining the tissue cagA status.

\section{References}

1. Talley NJ, Stanghellini V, Heading RC, Koch KL, Malagelada JR \& Tytgat GN (1999). Functional gastroduodenal disorders. Gut, 45 (Suppl 2): II-37-II-42.

2. Laine L, Schoenfeld P \& Fennerty MB (2001). Therapy for Helicobacter pylori in patients with nonulcer dyspepsia. A meta-analysis of randomized, controlled trials. Annals of Internal Medicine, 134: 361369.

3. Talley NJ, Silverstein MD, Agreus L, Nyren O, Sonnenberg A \& Holtmann G (1998). AGA technical review: evaluation of dyspepsia. American Gastroenterological Association. Gastroenterology, 114: 582-595.

4. Talley NJ (2002). Dyspepsia: management guidelines for the millennium. Gut, 50 (Suppl 4): IV-72-IV-78.

5. Talley NJ (1997). Dyspepsia and heartburn: a clinical challenge. Alimentary Pharmacology and Therapeutics, 11 (Suppl 2): 1-8.

6. Howden CW (1997). For what conditions is there evidence-based justification for treatment of Helicobacter pylori infection? Gastroenterology, 113 (Suppl 6): S107-S112.

7. Malfertheiner $P$, Megraud F, O'Morain $C$, Hungin AP, Jones R, Axon A, Graham DY \& Tytgat G (2002). Current concepts in the management of Helicobacter pylori infection - the Maastricht 2-2000 Consensus Report. Alimentary Pharmacology and Therapeutics, 16 : 167-180.

8. Hunt R \& Thomson AB (1998). Canadian Helicobacter pyloriconsensus conference. Canadian Association of Gastroenterology. Canadian Journal of Gastroenterology, 12: 31-41

9. Lam SK \& Talley NJ (1998). Report of the 1997 Asia Pacific Consensus Conference on the management of Helicobacter pylori infection. Journal of Gastroenterology and Hepatology, 13: 1-12.

10. Talley NJ, Meineche-Schmidt V, Pare P, Duckworth M, Raisanen P, Pap A, Kordecki H \& Schmid V (1998). Efficacy of omeprazole in functional dyspepsia: double-blind, randomized, placebo-controlled trials (the Bond and Opera studies). Alimentary Pharmacology and Therapeutics, 12: 1055-1065.

11. Dixon MF, Genta RM, Yardley JH \& Correa P (1996). Classification and grading of gastritis. The updated Sydney System. International Workshop on the Histopathology of Gastritis, Houston 1994. American Journal of Surgical Pathology, 20: 1161-1181.
12. Yamaoka Y, Kodama T, Kita M, Imanishi J, Kashima K \& Graham DY (1999). Relation between clinical presentation, Helicobacter pylori density, interleukin 1 beta and 8 production, and cagA status. Gut, 45: 804-811.

13. Censini S, Lange C, Xiang Z, Crabtree JE, Ghiara P, Borodovsky M, Rappuoli R \& Covacci A (1996). cag, a pathogenicity island of Helicobacter pylori, encodes type I-specific and disease-associated virulence factors. Proceedings of the National Academy of Sciences, USA, 93: 14648-14653.

14. Nelson DB, Murdoch $M$, Sandozi IK, Dalmasso AP, Crabtree JE \& Ho SB (2000). Dyspepsia is associated with CagA-positive Helicobacter pylori. American Journal of Gastroenterology, 95: 3412-3417.

15. Walsh JH \& Peterson WL (1995). The treatment of Helicobacter pylori infection in the management of peptic ulcer disease. New England Journal of Medicine, 333: 984-991.

16. Holtmann G, Goebell H, Holtmann M \& Talley NJ (1994). Dyspepsia in healthy blood donors. Pattern of symptoms and association with Helicobacter pylori. Digestive Diseases and Sciences, 39: 10901098.

17. Nandurkar S, Talley NJ, Xia H, Mitchell H, Hazel S \& Jones M (1998). Dyspepsia in the community is linked to smoking and aspirin use but not to Helicobacter pylori infection. Archives of Internal Medicine, 158: 1427-1433.

18. Gilvarry J, Buckley MJ, Beattie S, Hamilton H \& O'Morain CA (1997). Eradication of Helicobacter pylori affects symptoms in nonulcer dyspepsia. Scandinavian Journal of Gastroenterology, 32: 535540.

19. McColl K, Murray L, El-Omar E, Dickson A, El-Nujumi A, Wirz A, Kelman A, Penny C, Knill-Jones R \& Hilditch T (1998). Symptomatic benefit from eradicating Helicobacter pylori infection in patients with nonulcer dyspepsia. New England Journal of Medicine, 339: 1869-1874

20. Blum AL, Talley NJ, O'Morain C et al. (1998). Lack of effect of treating Helicobacter pylori infection in patients with nonulcer dyspepsia. Omeprazole plus Clarithromycin and Amoxicillin Effect One Year after Treatment (OCAY) Study Group. New England Journal of Medicine, 339: 1875-1881. 